\section{Restrição protéica na prenhez - efeitos relacionados ao metabolismo materno}

\author{
Protein restriction in pregnancy: effects related to dam metabolism
}

Marcia L. O. Ballen', Vera L. Moretto', Maisa P. dos Santos', Talita S. S. Gonçalves², Nair H. Kawashita ${ }^{1,3,4}$, Luis F. Stoppiglia ${ }^{4}$, Maria Salete F. Martins ${ }^{4,5}$, Maria Helena G. Gomes-da-Silva ${ }^{1,4,5}$

\section{RESUMO}

Foram avaliadas as alterações no metabolismo materno durante a prenhez em ratas Wistar, prenhes e não-prenhes, submetidas à restrição protéica, que receberam dietas isocalóricas (15,74 $\mathrm{kJ} / \mathrm{g}$ ), controle ou hipoprotéica ( $17 \%$ versus $6 \%)$, distribuídas em quatro grupos $(n=7)$, quais sejam: controle não-prenhe (CNP) e prenhe (CP) e hipoprotéico não-prenhe (HNP) e prenhe (HP), do $1^{\circ}$ ao $18^{\circ}$ dia de prenhez. Parâmetros bioquímicos, hormonais e relacionados à síntese de lipídios foram considerados. Utilizou-se ANOVA a duas vias seguido de teste Tukey-HSD e teste t de Student, significância de $p<0,05$. A restrição protéica elevou a síntese de lipídios e a atividade da enzima málica (EM) no fígado (FIG) e reduziu a massa (\%) e a razão lipí+dio/glicogênio nesse tecido, bem como reduziu a ingestão protéica (total e \%), o conteúdo (\%) de lipídios na glândula mamária (GMA), as proteínas e a albumina séricas, com consequente redução nas massas da placenta e fetos. A prenhez reduziu a proteinemia, a albuminemia, a síntese de lipídios, a atividade da EM, os lipídios e o glicogênio no FIG. Mas elevou a massa corporal final, a massa (\%) do tecido adiposo gonadal (GON), do FIG e da GMA, e reduziu a massa (\%) da carcaça (CARC), a síntese e o conteúdo de lipídios no GON e, na GMA, o conteúdo de lipídios. A insulinemia elevou-se na prenhez, com glicemia reduzida, caracterizando resistência hormonal. A leptina e a prolactina também se elevaram na prenhez, sendo o aumento maior no HP. A restrição protéica na prenhez modificou o metabolismo materno, alterando a síntese de lipídios no FIG e o perfil hormonal, além de reduzir a massa da placenta e dos fetos. Arq Bras Endocrinol Metab. 2009;53(1):87-94.

Descritores

Restrição protéica; prenhez; metabolismo materno

\begin{abstract}
Metabolism alterations were evaluated in female Wistar rats (dams) during pregnancy. Pregnant and non-pregnant dams submitted to protein restriction, were fed isocaloric $(15.74 \mathrm{~kJ} / \mathrm{g})$, control or hypoproteic ( $17 \%$ vs. $6 \%$ ) diets, and distributed in four Groups $(n=7)$ as follows: non-pregnant control (NPC), pregnant control (PC), non-pregnant hypoproteic (NPH), and pregnant hypoproteic $(\mathrm{PH})$; from Day 1 to Day 18 of pregnancy. Biochemical, hormonal and metabolic parameters related to lipid synthesis were assessed. The two-way ANOVA, followed by Tukey-HSD and Student-t tests were used, with a significance of $p<0.05$. Protein restriction elevated lipid synthesis and malic enzyme (ME) activity in the liver, and reduced mass and the lipid/glycogen ratio in this tissue; it also lowered protein ingestion (total and \%), lipid content (\%) in the mammary gland (MAG), serum proteins and albumin, with consequent reduction of placenta and fetal masses. Pregnancy reduced serum protein and albumin concentrations, lipid synthesis, ME activity, hepatic lipid and glycogen content. However, it increased final body mass; increased relative masses of gonad (GON), liver and MAG; but reduced lipid synthesis and content of GON, lipid content of MAG and the relative mass of carcass. Pregnancy Insulinemia increased during pregnancy with reduced glycemia, characterizing hormonal resistance. Leptin and prolactin were also increased during pregnancy, being the highest increase in observed in HP rats. Protein restriction in pregnancy modified maternal metabolism, altering lipid synthesis in the liver and hormonal profile and decreasing the placenta and fetus masses. Arq Bras Endocrinol Metab. 2009;53(1):87-94.
\end{abstract}

Keywords

Protein restriction; pregnancy; dam metabolism
Curso de Ciências da Saúde, Faculdade de Ciências Médicas (FCM), Universidade Federal de Mato Grosso (UFMT)

2 Faculdade de Nutrição (FANUT), UFMT

${ }^{3}$ Departamento de Química, Instituto de Ciências da Terra (ICET), UFMT

${ }^{4}$ Curso de Biociências, FANUT, UFMT ${ }^{5}$ Departamento de Alimentos e Nutrição, FANUT, UFMT;Cuiabá, MT, Brasil

Correspondência para:

Maria Helena Gaíva Gomes-da-Silva Departamento de Alimentos e Nutrição da Faculdade de Nutrição, UFMT Av. Fernando Correa da Costa, s/ nº - Coxipó

78060-900 Cuiabá, MT

marihele@ufmt.br

Recebido em 10/Jun/2008 Aceito em 19/Nov/2008 


\section{INTRODUÇÃO}

- studos descritos a partir das décadas de 1970 e 1980 ¿passaram a associar a restrição nutricional materna e, principalmente, a restrição protéica, não só com o retardo no crescimento intrauterino das crias, mas, principalmente, com a maior predisposição para o desenvolvimento de doenças crônicas na vida adulta, em particular a obesidade e o diabetes melito tipo 2 (1).

No Brasil, alguns estudos de prevalência mostraram aumento epidêmico de obesidade, principalmente entre mulheres pertencentes a classes sociais mais desfavorecidas $(2,3)$. Embora a melhora nas condições econômicas em algumas famílias possa explicar tais tendências, é possível que outros fatores também sejam importantes (4).

O acúmulo de proteínas durante a prenhez é essencial para o crescimento fetal e, nessa fase, tanto a síntese de proteínas quanto a retenção de nitrogênio encontram-se aumentadas em ambos os compartimentos: materno e fetal (5). O balanço nitrogenado torna-se melhorado e a proteína da dieta é utilizada de maneira mais eficiente (6) ao final da prenhez.

A restrição protéica e a prenhez quando associadas podem desencadear alterações na homeostase materna, manifestada por relativa hiperlipidemia e menor responsividade à insulina, o que pode minimizar o impacto do inadequado suprimento protéico para o crescimento fetal (7).

Nestas mesmas condições, tem sido observado estado de resistência à leptina. Não obstante a conhecida ação da leptina na inibição do apetite, podem ocorrer concentrações séricas elevadas desse hormônio, concomitantes com consumo alimentar estável ou mesmo aumentado $(8,9)$. A concentração plasmática e a ação da leptina parecem ser alteradas por dietas hipoprotéicas (10) e pela gravidez (9). A coexistência do consumo de dietas hipoprotéicas e gestação, comumente encontrada em países subdesenvolvidos, pode modificar o perfil sérico e a ação desses hormônios, contribuindo para a promoção da obesidade materna a curto e longo prazos.

Estudos em modelos animais, abordando os efeitos da desnutrição durante a prenhez e a lactação, têm relatado ocorrer comprometimento na massa corporal das mães, com repercussões nas crias $(11,12)$, como alterações permanentes no crescimento e no metabolismo, mudanças irreversíveis no tamanho e na função de órgãos, especialmente o fígado e o pâncreas (13), na composição corporal e na secreção de hormônios que atuam no crescimento fetal (14).

Macêdo e cols. (15) avaliaram em laboratório, na fase anabólica da prenhez (do $1^{\circ}$ ao $14^{\circ}$ dia), o efeito de dieta restrita em proteína sobre as concentrações séricas de leptina e insulina, e o envolvimento desses hormônios no comportamento alimentar e no acréscimo de gordura corporal em ratas. Observaram redução na glicemia e na proporção dos depósitos de tecido adiposo branco gonadal como efeito da prenhez, enquanto a restrição protéica diminuiu a proporção de gordura na carcaça. Porém, em todos os grupos as concentrações séricas de leptina e insulina foram similares e não se correlacionaram com a ingestão alimentar.

Encontra-se bem documentado que a segunda fase da prenhez (do $15^{\circ}$ dia ao final) é caracterizada pelo predomínio da atividade lipolítica no tecido adiposo, com liberação de substratos que serão reesterificados no fígado (16), incorporados em lipoproteínas de muito baixa densidade e liberados na circulação materna (17). Entretanto, muito poucos estudos têm associado a restrição protéica na prenhez com mudanças no metabolismo materno, em especial, com a atividade lipogênica nos tecidos e o perfil hormonal.

\section{MÉTODOS}

\section{ANIMAIS E DIETAS}

Os procedimentos experimentais obedeceram as recomendações do Colégio Brasileiro de Experimentação Animal (Cobea) (18), adotadas pela Universidade Federal de Mato Grosso (UFMT), e foram desenvolvidos no Laboratório de Avaliação Biológica de Alimentos (LABA) do Departamento de Alimentos e Nutrição da Faculdade de Nutrição (Fanut) da UFMT, Cuiabá, MT.

Ratas fềmeas Wistar, 90 dias, peso $\pm 250 \mathrm{~g}$, procedentes do Biotério Central da UFMT, foram mantidas em gaiolas individuais e divididas de acordo com o estado fisiológico (prenhe e não-prenhe) em quatro grupos, recebendo dietas isocalóricas $(15,74 \mathrm{~kJ} / \mathrm{g})$, quais sejam: hipoprotéico, $6 \%$ de proteína (não-prenhe e prenhe, HNP e HP) e controle, $17 \%$ de proteína (não-prenhe e prenhe, $\mathrm{CNP}$ e $\mathrm{CP}$ ), após a confirmação da prenhez e até o $18^{\circ}$ dia. As dietas foram preparadas conforme as recomendações do Instituto Americano de Nutrição (AIN 93-G) e descritas por Ferreira e cols. (19). As ratas não-prenhes e prenhes foram separadas em gaiolas individuais e mantidas em ambiente a $24 \pm 1{ }^{\circ} \mathrm{C}$, umidade relativa de $55 \%$ e ciclo claro das 6 às 18 horas, com dieta e água ad libitum.

\section{PROCEDIMENTOS EXPERIMENTAIS E DETERMINAÇÕES BIOQUÍMICAS E HORMONAIS}

Os consumos alimentares absoluto $(\mathrm{g})$ e relativo $(\mathrm{g} / \mathrm{l} 00$ $\mathrm{g})$ e as massas corporais inicial e final (g) foram registrados três vezes por semana, no período matutino, durante 
o período experimental. $\mathrm{O}$ consumo relativo foi obtido dividindo-se o consumo absoluto pela massa corporal final de cada rata, em percentual, sendo expresso como g de alimento/ $100 \mathrm{~g}$ de massa do animal, a fim de normalizar a ingestão de alimentos entre animais de massa corporal distinta. Para o cálculo da ingestão total de proteína, considerou-se o consumo total de cada rata, relacionado à concentração de proteína de cada dieta oferecida (17\% ou 6\%), sendo os valores expressos em g. A ingestão protéica relativa foi calculada considerando a ingestão protéica absoluta dividida pela massa corporal final de cada rata, em percentual.

Todos os procedimentos experimentais tiveram início às 7 horas. Inicialmente, foram coletadas amostras de sangue para a determinação da glicemia no estado alimentado, por meio de pequena incisão na extremidade inferior da cauda dos animais. Para a medida da velocidade de síntese de ácidos graxos, foram injetados em cada animal intraperitonealmente, $3 \mathrm{mCi}$ de ${ }^{3} \mathrm{H}_{2} \mathrm{O}$ contidos em $0,3 \mathrm{~mL}$ de salina, 60 minutos antes do sacrifício. Os animais foram eutanaseados com $\mathrm{CO}_{2}$, sendo posteriormente decapitados para a coleta de sangue, separando-se o soro e o plasma para avaliações bioquímicas, hormonais e para a determinação da atividade específica de ${ }^{3} \mathrm{H}_{2} \mathrm{O}$. Após laparotomia mediana foram retirados e pesados, $\mathrm{O}$ tecido adiposo branco gonadal (GON), a glândula mamária (GMA), o fígado (FIG) e a carcaça (CARC), obtendo-se a massa em valores absoluto $(\mathrm{g})$ e relativo (g/l00 g de massa corporal), sendo a seguir armazenados em freezer a $-80{ }^{\circ} \mathrm{C}$ para posteriores análises. Mensurou-se, ainda, a massa da placenta das ratas $\mathrm{e}$, dos fetos, foram obtidos o número e a massa $(\mathrm{g})$.

A glicose sérica, expressa em mg/dL, foi determinada utilizando-se monitor com tiras de teste para determinação da glicemia (glicosímetro) por fotômetro de refletância da marca Accu-Chek®, Laboratório Roche Diagnósticos, Alemanha. As proteínas totais foram expressas em $\mathrm{g} / \mathrm{dL}$ e determinadas de acordo com o método de reativo de biureto descrito por Wolfson e cols. (20), e a albumina, expressa em $\mathrm{g} / \mathrm{dL}$, foi dosada segundo o método colorimétrico do verde de bromocresol, descrito por Doumas, Watson e Biggs (21).

O conteúdo de glicogênio no FIG foi expresso em mg de glicogênio/100 mg de peso fresco de tecido hepático, e determinado conforme o método descrito por Sjögren e cols. (22). O conteúdo de lipídios no GON, na GMA e no FIG foi avaliado pelo método descrito por Folch, Less e Stanley (23), e expresso em mg de lipídio/100 mg de peso fresco dos tecidos. As concentrações hormonais foram determinadas por Elisa, utilizando-se kits comercialmente disponíveis: insulina, expressa em pg/mL: Rat Insulin Elisa Kit - Linco Research, USA; prolactina em ng/mL: Rat Prolactin EIA - ALPCO
Diagnostics, USA; leptina em pg/mL: Antigenix América's Leptin Elisa Consctruction Kit, Inc. USA; e glucagon, expresso em pg/mL: Rat Glucagon Elisa Kit Wako, USA.

A velocidade de síntese de ácidos graxos (AG) foi medida no FIG, no GON e na GMA dos grupos avaliados, por meio da incorporação de ${ }^{3} \mathrm{H}_{2} \mathrm{O}$ em lipídios, consoante descrito por Robinson, Girard e Williamson (24). Alíquotas de $500 \mathrm{mg}$ dos tecidos foram saponificados com $\mathrm{KOH}$, a seguir os ácidos graxos foram extraídos em mistura clorofórmio/metanol 2:1, e o conteúdo de lipídios foi mensurado após a evaporação do solvente. A taxa de lipogênese de novo in vivo nos tecidos foi expressa como micromoles de ${ }^{3} \mathrm{H}_{2} \mathrm{O}$ incorporados em lipídios por hora e por grama de tecido, como descrito por Gaíva e cols. (25).

A atividade das enzimas no FIG: glicose-6-P-desidrogenase (G6PDH) avaliada segundo o método de Lee (26), a enzima málica $(\mathrm{EM})$, pelo método descrito por Ochoa (27) e modificado por Hsu e Lardy (28) e a ATP-citrato liase (ATP-Cit) pelo método descrito por Srere (29), foram expressas em nmol de $\mathrm{NADP}^{+} / \mathrm{mg}$ de proteína.min. $\mathrm{O}$ conteúdo protéico do homogenado foi determinado pelo método de Lowry e cols. (30).

\section{ANÁLISE ESTATÍSTICA}

Os resultados foram apresentados em média e erropadrão da média (EPM) com o número de animais indicados entre parênteses. Todas as análises foram submetidas ao teste de Bartlett para verificar a homogeneidade das variâncias. Os resultados com variâncias heterogêneas e sem distribuição normal foram inicialmente transformados (logaritmo- $\log _{10}$ ) para correção da heterogeneidade ou anormalidade. Ao comparar os grupos, utilizou-se a análise de variância (ANOVA) a dois fatores (estado nutricional e estado fisiológico), seguido por teste de comparações múltiplas de médias (Tukey HSD para grupos com $\mathrm{n}$ iguais e diferentes). Quando comparados apenas dois grupos, os valores obtidos foram avaliados pelo teste $\mathrm{t}$ de Student para amostras independentes. Estabeleceu-se o nível de significância para rejeição da hipótese de nulidade de $5 \%$ $(\mathrm{p}<0,05)$.

\section{RESULTADOS}

O consumo alimentar absoluto foi aumentado nas ratas prenhes e, quando expresso em proporção à massa corporal final, ocorreu consumo similar entre os grupos HNP e HP comparados aos grupos CNP e CP. A restrição protéica na dieta determinou redução no consumo 
de proteínas em termos absoluto e relativo nos grupos HNP e HP. Os grupos prenhes, comparados aos nãoprenhes, tiveram consumo mais elevado de proteínas em termos absolutos e, em termos relativos, o CP consumiu menos proteína que o CNP. A massa corporal final das ratas prenhes foi significativamente mais elevada do que a das não-prenhes (Tabela 1 ).

Tabela 1. Consumos alimentares absoluto e relativo, ingestões protéicas absoluta e relativa e massas corporais inicial e final de ratas não-prenhes e prenhes tratadas com dieta-controle (CNP e $\mathrm{CP}$ ) ou hipoprotéica (HNP e HP) durante 18 dias de prenhez.

\begin{tabular}{|c|c|c|c|c|}
\hline & \multicolumn{4}{|c|}{ Grupos $(n=7)$} \\
\hline & CNP & $\mathrm{CP}$ & HNP & HP \\
\hline $\begin{array}{l}\text { Consumo } \\
\text { absoluto (g) }\end{array}$ & $280 \pm 10$ & $344 \pm 18^{\star \star \star}$ & $271 \pm 10$ & $371 \pm 9^{\star \star \star}$ \\
\hline $\begin{array}{l}\text { Consumo relativo } \\
(\mathrm{g} / 100 \mathrm{~g})\end{array}$ & $107 \pm 3 b$ & $96 \pm 3 a$ & $98 \pm 3 a b$ & $106 \pm 2 a b$ \\
\hline $\begin{array}{l}\text { Ingestão protéica } \\
\text { absoluta (g) }\end{array}$ & $48 \pm 1,77$ & $58 \pm 3,09^{\star \star \star}$ & $16 \pm 0,61 \# \# \#$ & $22 \pm 0,51^{\star \star \star} \# \# \#$ \\
\hline $\begin{array}{l}\text { Ingestão protéica } \\
\text { relativa (g/100 g) }\end{array}$ & $18 \pm 0,5 c$ & $16 \pm 0,5 b$ & $6,0 \pm 0,2 \mathrm{a}$ & $6,0 \pm 0,1 \mathrm{a}$ \\
\hline $\begin{array}{l}\text { Massa corporal } \\
\text { inicial }(\mathrm{g})\end{array}$ & $234 \pm 3$ & $250 \pm 7$ & $250 \pm 5$ & $249 \pm 10$ \\
\hline $\begin{array}{l}\text { Massa corporal } \\
\text { final }(\mathrm{g})\end{array}$ & $260 \pm 4$ & $358 \pm 9^{\star \star \star}$ & $280 \pm 8$ & $351 \pm 10^{\star \star \star}$ \\
\hline
\end{tabular}

Valores representam média \pm EPM de 7 animais. ${ }^{* * *} p<0,001$ comparado às ratas não-prenhes (ANOVA a dois fatores); \#\# $\mathrm{p}<0,001$ comparado às ratas-controle (ANOVA a dois fatores); letras diferentes indicam diferenças estatísticas (teste de Tukey HSD; $p<0,001)$.

As concentrações séricas de proteínas totais e albumina foram significativamente reduzidas, tanto pela prenhez quanto pela restrição protéica. Entretanto, a glicemia e o conteúdo de glicogênio hepático foram reduzidos apenas pela prenhez, sendo este mais elevado no grupo HP comparado ao $\mathrm{CP}$ (dados não apresentados).
A restrição protéica materna provocou redução nas massas da placenta e dos fetos, quando comparados aos controles, não alterando, entretanto, o número de fetos entre os grupos (Figura 1).

Com o efeito da prenhez ocorreu aumento na massa total do FIG, do GON e da CARC. Quando expresso em $\mathrm{g} / 100 \mathrm{~g}$, observou-se aumento da massa do FIG por causa da prenhez e da redução pela restrição protéica. Na CARC, a prenhez reduziu a massa proporcional. E na GMA, em valores absolutos e relativos, ocorreu aumento da massa tanto como efeito da restrição de proteínas quanto da prenhez (Tabela 2). Em relação ao conteúdo proporcional de lipídios nos tecidos, foi observada redução no FIG e no GON pela

Tabela 2. Massas absoluta e relativa dos tecidos e carcaças (g) de ratas não-prenhes e prenhes tratadas com dieta-controle (CNP e CP) ou hipoprotéica (HNP e HP) durante 18 dias de prenhez.

\begin{tabular}{|c|c|c|c|c|}
\hline & \multicolumn{4}{|c|}{ Grupos (n=7) } \\
\hline & CNP & $\mathrm{CP}$ & HNP & HP \\
\hline & \multicolumn{4}{|c|}{ g } \\
\hline FIG & $8,28 \pm 0,29$ & $12,30 \pm 0,38^{* \star *}$ & $8,09 \pm 0,41$ & $11,35 \pm 0,37^{\star \star \star}$ \\
\hline GON & $11,46 \pm 0,81$ & $18,01 \pm 1,83^{\star \star}$ & $15,05 \pm 1,42$ & $16,84 \pm 1,48^{\star *}$ \\
\hline GMA & $5,45 \pm 0,37$ & $12,70 \pm 0,97^{\star \star \star}$ & $8,18 \pm 0,72^{\# \#}$ & $15,04 \pm 1,02^{\star \star \star \star ⿰ 扌 \sharp ~}$ \\
\hline CARC & $188 \pm 2,77$ & $218 \pm 3,99^{* * *}$ & $200 \pm 4,19$ & $220 \pm 6,59^{\star \star *}$ \\
\hline \multicolumn{5}{|c|}{$g / 100 g$} \\
\hline FIG & $3,20 \pm 0,12$ & $3,44 \pm 0,05^{\star}$ & $2,92 \pm 0,14^{*}$ & $3,24 \pm 0,13^{* \#}$ \\
\hline GON & $4,43 \pm 0,35$ & $4,99 \pm 0,41$ & $5,38 \pm 0,37$ & $4,75 \pm 0,30$ \\
\hline GMA & $2,09 \pm 0,13$ & $3,53 \pm 0,19^{\star * *}$ & $2,94 \pm 0,20^{\# \# *}$ & $4,26 \pm 0,22^{\star \star \star \star \# \#}$ \\
\hline CARC & $72,71 \pm 0,56$ & $61,09 \pm 0,69^{\star \star \star}$ & $72,22 \pm 0,64$ & $62,51 \pm 0,27^{\star \star \star}$ \\
\hline
\end{tabular}

Valores expressam média \pm EPM de 7 animais; ${ }^{*} p<0,05 ;{ }^{* *} p<0,01 ;{ }^{* * \star} p<0,001$ comparado às ratas não-prenhes (ANOVA a dois fatores); $\mathrm{\#}<<0,05$; ${ }^{\# \#} \mathrm{p}<0,01$; ${ }^{\# \#} \mathrm{p}<$ 0,001 comparado às ratas-controle (ANOVA a dois fatores).
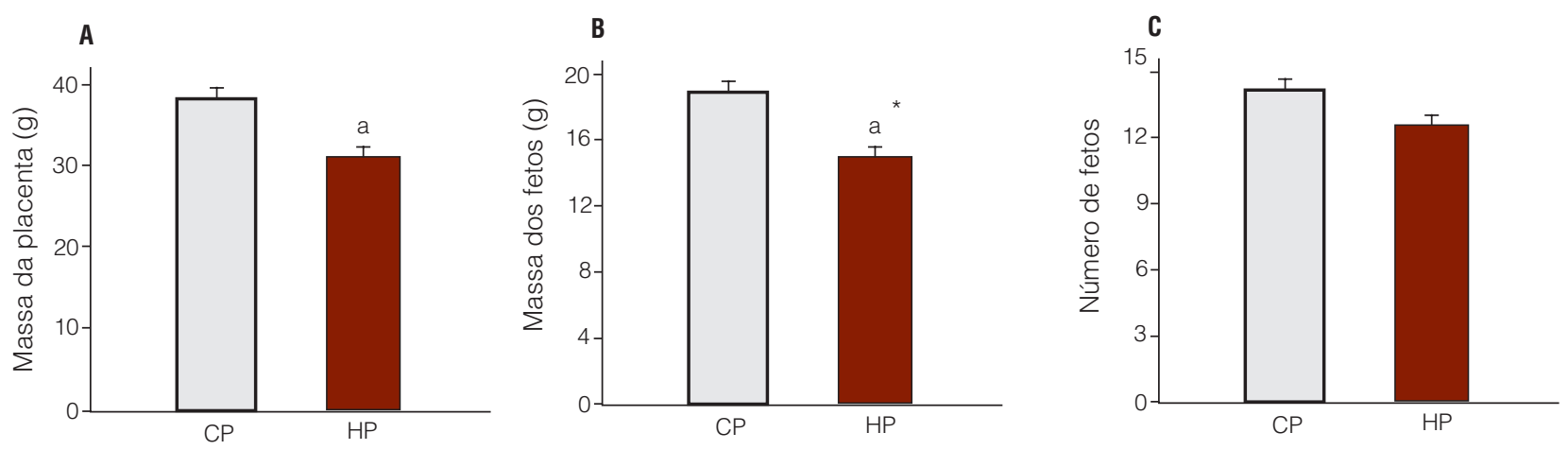

${ }^{a} p<0,001 \mathrm{e}^{\mathrm{a}^{*}} \mathrm{p}<0,001$ comparado às ratas-controle (teste $\mathrm{t}$ de Student).

Figura 1. Massa (g) da placenta (A), dos fetos (B) e número de fetos (C) de ratas prenhes, tratadas com dieta-controle (CP) ou hipoprotéica (HP) durante 18 dias de prenhez. Os valores expressam média \pm EPM de 7 animais. 
prenhez. Na GMA, ocorreu menor conteúdo percentual de lipídios, tanto na prenhez quanto na restrição protéica.

A razão lipídio/glicogênio no FIG foi aumentada em virtude da prenhez, mas foi reduzida pela restrição protéica na dieta (Tabela 3 ).

Tabela 3. Conteúdo de lipídios no FIG, no GON e na GMA ( $\mathrm{mg} / 100 \mathrm{mg}$ ) e razão lipídio/glicogênio, das ratas dos grupos nãoprenhes e prenhes tratadas com dieta-controle (CNP e CP) ou hipoprotéica (HNP e HP) durante 18 dias de prenhez.

\begin{tabular}{lcccc}
\hline & \multicolumn{4}{c}{ Grupos $(\mathbf{n}=7)$} \\
& CNP & CP & HNP & HP \\
\hline FIG & $5,92 \pm 0,15$ & $3,94 \pm 0,08^{* *}$ & $4,90 \pm 0,22$ & $4,16 \pm 0,12^{* *}$ \\
GON & $73,88 \pm 0,32$ & $67,63 \pm 0,58^{* * *}$ & $70,93 \pm 0,21$ & $67,21 \pm 0,37^{* * *}$ \\
GMA & $66,15 \pm 0,76$ & $58,45 \pm 1,02^{*}$ & $57,48 \pm 1,61^{\#}$ & $52,72 \pm 0,71^{* *}$ \\
Razão & & & & \\
lipídio/ & $0,85 \pm 0,1$ & $1,65 \pm 0,1^{* * *}$ & $0,75 \pm 0,1^{*}$ & $1,18 \pm 0,1^{* * * *}$ \\
glicogênio & & & & \\
\hline
\end{tabular}

Valores expressam média \pm EPM de 7 animais; ${ }^{*} p<0,05 ;{ }^{* \star} p<0,001 ;{ }^{* \star *} p<0,001$ comparado às ratas não-prenhes (ANOVA a dois fatores); $\# p<0,05$ comparado às ratas-controle (ANOVA a dois fatores).

Observou-se que a insulinemia foi mais elevada no grupo de ratas prenhes. No entanto, nas ratas HP esse aumento foi significativamente menor que o encontrado no CP. Quanto às concentrações de leptina e prolactina, observou-se que foram influenciadas tanto pela restrição protéica quanto pela prenhez. A restrição protéica elevou em cerca de cinco vezes a leptinemia. Nos animais-controle a prenhez aumentou em cinco vezes a leptinemia (CP versus $\mathrm{CNP}$ ) e o $\mathrm{HP}$ foi duas vezes maior que o HNP.

A concentração de prolactina aumentou acima de duas vezes nos grupos restritos em proteína (HP e HNP) comparados aos controles. A prenhez também provocou aumento significativo desse hormônio, sendo de uma vez e meia no $\mathrm{HP}$ e de sete vezes no $\mathrm{CP}$, comparados aos nãoprenhes (Tabela 4).

Tabela 4. Concentrações séricas de insulina, glucagon, leptina e prolactina, de ratas não-prenhes e prenhes tratadas com dietacontrole (CNP e CP) ou hipoprotéica (HNP e HP) durante 18 dias de prenhez.

\begin{tabular}{lcccc}
\hline & \multicolumn{4}{c}{ Grupos $(\mathbf{n}=\mathbf{5})$} \\
& CNP & CP & HNP & HP \\
\hline $\begin{array}{l}\text { Insulina } \\
\text { ( } \mathrm{pg} / \mathrm{mL})\end{array}$ & $1.590 \pm 380$ & $4.540 \pm 770^{* *}$ & $1.570 \pm 370$ & $2.290 \pm 620^{* *}$ \\
$\begin{array}{l}\text { Glucagon } \\
\text { (pg/mL) }\end{array}$ & $440 \pm 100$ & $800 \pm 100$ & $450 \pm 100$ & $530 \pm 100$ \\
$\begin{array}{l}\text { Leptina } \\
\text { (pg/mL) }\end{array}$ & $2.890 \pm 490$ & $9.000 \pm 179^{* * *}$ & $17.610 \pm 294^{\# \#}$ & $39.810 \pm 450^{\# \# *}$ \\
$\begin{array}{l}\text { Prolactina } \\
\text { (ng/mL) }\end{array}$ & $0,5 \pm 0,1$ & $3,8 \pm 1,5^{*}$ & $4,6 \pm 1,3^{\# \#}$ & $7,0 \pm 1,4^{\# * *}$ \\
\hline
\end{tabular}

Valores expressam média \pm EPM de 5 animais; ${ }^{*} p<0,05 ;{ }^{* \star} p<0,01 ;{ }^{* \star \star} p<0,001$ comparado às ratas não-prenhes (ANOVA a dois fatores); ${ }^{\#} p<0,05 ;{ }^{\# \#} p<0,01$; \#\#\# $\mathrm{p}<0,001$ comparado às ratas-controle (ANOVA a dois fatores).
A restrição de proteínas aumentou a velocidade de síntese de ácidos graxos no FIG, mas esta foi reduzida pela prenhez. Na GMA, o grupo HNP apresentou maior velocidade de síntese que os demais e, no GON, ocorreu redução em virtude da prenhez (Tabela 5).

Tabela 5. Velocidade de síntese de ácidos graxos medida pela incorporação de 3H20 no FIG, no GON e na GMA ( $\mu \mathrm{mol}$ g. -1 h.-1) e atividade das enzimas no FIG (nmol.mg de prot.-1 min.-1) de ratas não-prenhes e prenhes, tratadas com dieta-controle (CNP e CP) ou hipoprotéica (HNP e HP) durante 18 dias de prenhez.

\begin{tabular}{lcccc}
\hline & \multicolumn{3}{c}{ Grupos $(\mathbf{n}=\mathbf{5})$} \\
& CNP & CP & HNP & HP \\
\hline FIG & $0,95 \pm 0,22$ & $0,66 \pm 0,06^{*}$ & $1,87 \pm 0,44^{\#}$ & $0,91 \pm 0,13^{*}$ \\
GON & $0,19 \pm 0,02$ & $0,13 \pm 0,01^{*}$ & $0,29 \pm 0,08$ & $0,15 \pm 0,02^{*}$ \\
GMA & $0,30 \pm 0,05^{\mathrm{a}}$ & $0,18 \pm 0,06^{\mathrm{a}}$ & $0,75 \pm 0,05^{\mathrm{b}}$ & $0,36 \pm 0,9^{\mathrm{a}}$ \\
G6PDH & $278 \pm 36^{\mathrm{b}}$ & $117 \pm 14^{\mathrm{a}}$ & $292 \pm 15^{\mathrm{b}}$ & $185 \pm 5^{\mathrm{b}}$ \\
EM & $58 \pm 8$ & $33 \pm 4^{*}$ & $68 \pm 11^{*}$ & $56 \pm 7^{\text {* }}$ \\
ATP-cit & $128 \pm 28^{\mathrm{c}}$ & $64 \pm 7^{\mathrm{a}}$ & $98 \pm 11^{\mathrm{b}}$ & $95 \pm 11^{\mathrm{b}}$ \\
\hline
\end{tabular}

Valores expressam média \pm EPM de 5 animais; * $p<0,05$ comparado às ratas nãoprenhes (ANOVA a dois fatores); $" \mathrm{p}<0,05$ comparado às ratas-controle (ANOVA a dois fatores); letras diferentes indicam diferenças estatísticas (teste de Tukey HSD; $p<0,05)$.

A atividade das enzimas avaliadas no FIG mostrou que a EM foi significativamente aumentada pela restrição protéica e diminuída pela prenhez. A restrição protéica não modificou a atividade da G6PDH, porém no grupo-controle prenhe esta foi reduzida em relação aos demais grupos. A enzima ATP-cit teve atividade semelhante nos grupos restritos em proteína (HNP e HP), sendo estes maiores que a do grupo CP e menores que do CNP (Tabela 5 ).

\section{DISCUSSÃO}

A restrição protéica na dieta de ratas prenhes aumentou a velocidade de síntese de ácidos graxos, acompanhada de aumento na atividade da enzima málica no FIG, embora tenha provocado redução na massa relativa desse tecido e menor razão lipídio/glicogênio.

$\mathrm{O}$ aumento na velocidade de produção hepática de ácidos graxos, acompanhada da maior atividade da EM observada nos grupos submetidos à restrição protéica, mostra que a síntese de ácidos graxos de novo é bastante responsiva a mudanças na dieta.

No presente estudo, o aporte de carboidratos na dieta das ratas foi aumentado em substituição às proteínas, para manter as dietas isocalóricas. Alguns estudos na literatura demonstram que o aumento na oferta de carboidratos estimula a síntese de ácidos graxos no FIG, os quais são liberados na circulação, elevando as concentrações de triacilgli- 
cerol no plasma $(31,32)$. Diferentes condições nutricionais e hormonais $(33,34)$ também podem alterar a atividade das enzimas lipogênicas no FIG, que podem ser estimuladas pela insulina e deprimidas pelo glucagon (35).

Por outro lado, foi observado no FIG, redução na velocidade de síntese de ácidos graxos e na atividade da EM como efeito da prenhez, e também redução no conteúdo de lipídios e glicogênio. Porém, as massas total e percentual e a razão lipídio/glicogênio foram aumentadas nesse tecido. Foi observado, ainda, que a prenhez reduziu a síntese de ácidos graxos e o conteúdo de lipídios no GON, acompanhada de menor concentração de gordura na GMA.

A insulinemia apresentou elevação significante nas ratas prenhes, porquanto sua concentração nesses grupos foi, aproximadamente, duas vezes mais elevada, comparada à dos não-prenhes. A fase tardia da prenhez (terço final) se caracteriza por intensa quebra dos estoques de lipídios, com lipólise acentuada no tecido adiposo (36), acompanhada de reduzida captação de triacilgliceróis circulantes por esse tecido (37). Encontra-se bem documentado que o estado de hiperinsulinemia e resistência à insulina (38) podem ser responsáveis pelas várias mudanças metabólicas observadas nesse último estágio (39). O aumento nas concentrações plasmáticas de insulina e a redução na glicemia encontrados nas ratas prenhes sugerem estado de resistência à insulina típica da prenhez tardia, o que também pode ter sido confirmado pelo menor armazenamento de glicogênio no FIG $(40,41)$.

$\mathrm{Na}$ fase catabólica da prenhez, pode ocorrer hipoglicemia, pois ocorre redução no consumo desse substrato pelos tecidos maternos e aumento de sua transferência para o feto (42), sendo que isso corresponde à captação de $50 \%$ da glicose total utilizada pela mãe $(43,44)$.

A leptinemia aumentou em consequência da prenhez, porém, nos grupos restritos em proteína houve elevação muito acentuada nas concentrações desse hormônio. A hiperleptinemia pode estar relacionada com a resistência à insulina na prenhez (45), contribuindo para manter o consumo alimentar elevado, estimular o crescimento fetal e garantir as demandas para a lactação (46).

Resistência à leptina também tem sido observada durante a prenhez, podendo estar associada com redução na expressão de receptores hipotalâmicos de leptina e à menor fosforilação do fator de transcrição (STAT3) no núcleo hipotalâmico ventromedial, que regula ao mesmo tempo a ingestão alimentar e o gasto de energia $(47,48)$.

Consistente com o papel proposto da leptina como fator de crescimento fetal, Smith e Waddell (49) mostraram que a passagem transplacental de leptina materna, que se encontra significativamente aumentada na fase final da pre- nhez, representa fonte importante desse hormônio para o feto. Existem evidências sugerindo que a produção de leptina na placenta, no tecido adiposo fetal e sua concentração na circulação materna em roedores, agem pela ação de receptores de leptina fetais para regular o crescimento e o desenvolvimento do feto. Assim, as concentrações de leptina sérica e do cordão umbilical encontram-se positivamente correlacionadas com o peso ao nascer e com a adiposidade neonatal (49).

Esse estado de resistência à leptina observado no presente estudo nos grupos prenhes, parece ter favorecido a manutenção do consumo alimentar e garantido o desenvolvimento adequado da placenta e dos fetos no grupocontrole prenhe. Entretanto, no grupo HP, não obstante a hiperleptinemia, isso não ocorreu, pois houve redução acentuada nas massas, tanto da placenta quanto dos fetos, sugerindo interferência da restrição protéica no processo de desenvolvimento fetal.

Alguns estudos mostram que a redução na ingestão alimentar durante a prenhez ou a alteração na ingestão de proteínas são deletérias à formação fetal e ao desenvolvimento da gravidez, podendo desencadear, por vezes, quadros de desnutrição e nascimento de crias com massa corporal reduzida $(50,51)$. Embora neste estudo o consumo alimentar tenha sido semelhante entre os grupos, a ingestão de proteínas foi reduzida em termos absolutos e relativos pela restrição protéica. Adicionalmente, a ocorrência de hipoproteinemia e hipoalbuminemia, em consequência tanto da prenhez quanto da restrição protéica, pode ter contribuído também para a redução na massa dos fetos.

A prolactina, assim como a leptina, apresentou aumento tanto em função da prenhez quanto da restrição protéica, porquanto no grupo prenhe restrito em proteína (HP), a concentração desse hormônio foi aproximadamente duas vezes maior que no $C P$ e, mesmo no grupo não-prenhe restrito em proteína (HNP), as concentrações de prolactina elevaram-se de maneira significativa, sugerindo resistência hipotalâmica decorrente da restrição de proteínas na dieta.

Conforme descrito por Grattan e cols. (52), a prolactina é o único hormônio que se mantém elevado durante a prenhez, o puerpério e a lactação. A hiperprolactinemia na prenhez pode também contribuir na indução da resistência à leptina, aumentando a ingestão alimentar (52).

$\mathrm{Na}$ metade final da prenhez, a elevação desse hormônio favorece as importantes adaptações metabólicas do organismo materno à gravidez, sendo fator importante para o crescimento e a função da glândula mamária, para a secreção láctea (53), para estimular o desenvolvimento do comportamento maternal nas mães imediatamente após o parto, além de contribuir para outras respostas adaptativas no organismo materno (52). 
No presente estudo, observou-se que a restrição protéica durante 18 dias de prenhez promoveu aumento na atividade lipogênica no fígado materno, modificou o perfil hormonal e interferiu no desenvolvimento adequado da prenhez, reduzindo a massa da placenta e dos fetos.

Agradecimentos: Os autores agradecem a Celso Roberto Afonso pelo auxílio técnico, ao suporte financeiro da Fundação de Amparo à Pesquisa do Estado de Mato Grosso/Fapemat (Projeto no 175/2004) e à bolsa de iniciação científica IC/Fapemat concedida à Talita de Souza Schmidt Gonçalves.

Declaração: Os autores declaram que não existe qualquer conflito de interesse científico neste artigo.

\section{REFERÊNCIAS}

1. Desai M, Babu J, Ross MG. Programmed metabolic syndrome: prenatal undernutrition and postweaning overnutrition. Am J Physiol Regul Integr Comp Physiol. 2007;293:6:2306-14.

2. Florêncio TT. Obesity in adult population residing in a "sem teto" - homeless encampment in the northeast of Brazil. Int J Obes. 1998;22:S245.

3. Monteiro CA, Mondini L. The changing nature of nutrition disorders in the developing countries: the case of Brazil. Proceedings of the 16th International Congress of Nutrition, Montreal: Canadian Federation of Biological Science; 1998.

4. Popkin BM, Bisgrove ES. Urbanization and nutrition in low-income countries. Food Nutr Bull. 1988;10:3-23.

5. Satish CK. Protein metabolism in pregnancy. Am J Clin Nutr. 2000;71:S1249-55.

6. Mojtahedi M, Groot LCPGM, Boekholt HA, Raaij JMA. Nitrogen balance of healthy dutch women before and during pregnancy. Am J Clin Nutr. 2002;75:1078-83.

7. Sugd MC, Holness MJ. Modulation of in vivo insulin action by dietary protein during pregnancy. Am J Physiol. 1995;268:E722-9.

8. Fangyan Du, Higginbothan DA, Douglas BW. Food intake, energy balance and serum leptin concentrations in rats fed low protein diets. Faseb J. 1999;213:A225.

9. Seeber RM, Smith JT, Waddell BJ. Plasma leptin binding activity and hypothalamic leptin receptor expression during pregnancy and lactation in the rat. Biol Reprod. 2002;66:1762-7.

10. Du F, Higginbotham DA, White BD. Food intake, energy balance and serum leptin concentrations in rats fed low-protein diets. J Nutr. 2000;130:514-21.

11. McMillen IC, MacLaughlin SM, Muhlhausler BS, Gentili S, Duffield JL, Morrison JL. Developmental origins of adult health and disease: the role of periconceptional and foetal nutrition. Basic Clin Pharmacol Toxicol. 2008;102:82-9.

12. Schuler SL, Gurmini J, Cecílio WAC, Azevedo MLV, Olandoski M, Noronha L. Hepatic and thymic alterations in newborn offspring of malnourished rat. JPEN J Parenter Enteral Nutr. 2008;32:184-9.

13. Minana-Solis MC, Escobar C. Increased susceptiblity to metabolic alterations in Young adult females exposed to early malnutrition. Int $\mathrm{J}$ Biol Sci. 2007;3:12-9.

14. Patrício FRS, Nóbrega FJ, Tonete SSO. Desnutrição intra-uterina em diferentes períodos de gestação em ratas: estudo do intestino delgado proximal ao nascimento e durante a recuperação nutricional. Rev Paul Pediatr. 1984;2:43-52.

15. Macêdo GS, Ferreira CLP, Menegaz A, Arantes VC, Veloso RV, Carneiro $E M$, et al. Correlation of serum leptin and insulin levels of pregnant protein-restricted with predictive obesity variables. Braz J Med Biol Res. 2008;41(6):519-25.

16. Mampel T, Villarroya F, Herrera E. Hepatectomy-nephrectomy effects in the pregnant rat and fetus. Biochem Biophys Res Commun. 1985;131:1219-25.

17. Mason TM. The role of factors that regulate the synthesis and secretion of very low density lipoprotein by hepatocytes. Crit Rev Clin Lab Sci. 1988;35:461-87.

18. Manual para técnicos em laboratórios - Comissão de Ensino do Colégio Brasileiro de Experimentação Animal (Cobea). 2. ed. São Paulo: Finep-Cobea; 1996.

19. Ferreira CLP, Macêdo GM, Latorraca MQ, Arantes VC, Veloso RV, Carneiro EM, et al. Serum leptin and insulin levels in lactating protein-restricted rats: implications for energy balance. Br J Nutr. 2007;97:27-34.

20. Wolfson WQ, Cohn C, Calvary F, Ichiba F. Studies in serum proteins 5. A rapid procedure for the estimation of total protein, true albumin, total globulin, alpha globulin, and gamma globulin in $1.0 \mathrm{ml}$ of serum. Am J Clin Pathol. 1948;18:723-30.

21. Doumas BT, Watson WA, Biggs HG. Albumin standards and the measurements of serum albumin with bromocresol green. Clin Chim Acta. 1971;31:87-96.

22. Sjögren B, Koning WA, Holmgeen $H$, Möllersöm EJ. Betrag zur Kennynies der leberrthytlmik (glycogen, phosphor und calcium in des kaninchenleber). Pflüger Arch Ges Physiol. 1938;240:427-36.

23. Folch J, Less M, Stanley GA. A simple method for the isolation and purification of total lipids from animal tissues. J Biol Chem. 1957;226:497-509.

24. Robinson AM, Girard JR, Williamson DH. Evidence or a role of insulin regulation of lipogenesis in lactanting rat mammary gland. measurements of lipogenesis in vivo and plasma hormone concentrations in response to starvation and refeeding. Biochem J. 1978;170:609-13.

25. Gaíva MH, Couto RC, Oyama LM, Couto GEC, Silveira VLF, Ribeiro EB, et al. Diets rich in polyunsaturated fatty acids: Effect on hepatic metabolism in rats. Nutrition. 2003;19:144-9.

26. Lee CY. Glucose-6-phosphate dehydrogenase from mouse. Methods Enzymol. 1982;89 Pt D:559-62.

27. Ochoa S. Malic enzyme. Methods Enzymol. 1955;1:739-53.

28. Hsu RY, Lardy HA, Cleland WW. Pigeon liver malic enzyme. V. Kinetic studies. J Biol Chem. 1967;242:5315-22.

29. Srere PA. The citrate cleavage enzyme. Distribution and purification. J Biol Chem. 1959;234:2544-7.

30. Lowry $\mathrm{OH}$. Protein measurement with of the folin phenol reagent. J Biol Chem. 1951;193:265-8.

31. Jump DB, Clarke SD, Thelen A, Liimatta M. Coordinate regulation of glycolytic and lipogenic gene expression by polyunsaturated fatty acids. J Lipid Res. 1994;35:1076-84.

32. Kersten S, Seydoux J, Peters JM, Gonzalez FJ, Desvergne B, Wahli W. Peroxisome proliferator-activated receptor $\alpha$ mediates the adaptive response to fasting. J Clin Invest. 1999;103:1489-98.

33. Roncari DAK, Murthy WK. Lipogenesis and cholesterogenesis de novo in liver and adipose. J Biol Chem. 1975;250:4134-8.

34. Romsos DR, Leveille GA. Effect of diet on activity of enzymes involved in fatty acid and cholesterol synthesis. Adv Lipid Res. 1974;12:97-146.

35. Witters LA, Moriarity D, Martin DB. Microsomal acetyl-CoA carboxylase: evidence for association of enzyme polymer with liver microsomes. J Biol Chem. 1979;254:6644-9.

36. Martin-Hidalgo A, Holm C, Belfrage P, Schotz MC, Herrera E. Lipoprotein lipase and hormone-sensitive lipase activity and mRNA in rat adipose tissue during pregnancy. Am J Physiol. 1994;266:E930-5.

37. Herrera E, Gomez-Coronado D, Lasunción MA. Lipid metabolism in pregnancy. Biol Neonate. 1987;51:70-7.

38. Herrera E, Amusquivar E, López-Soldado I, Ortega H. Maternal lipid metabolism and placental lipid transfer. Horm Res. 2006;65:59-64. 
39. Ramos P, Herrera E. Comparative responsiveness to prolonged hyperinsulinemia between adipose-tissue and mammary gland lipoprotein lipase activities in pregnant rats. Early Pregnancy. 1996;2:29-35.

40. Rossi G, Lapaczewski P, Diamond MP, Jacob RJ, Shulman GI, Sherwin RS. Inhibitory effect of pregnancy on counterregulatory hormone responses to hypoglycemia in awake rat. Diabetes. 1993;42:1440-5.

41. Cryer PE, Davis SN, Shamoon H. Hypoglycemia in diabetes. Diabetes Care. 2003;26:1902-12.

42. Ramos $P$, Herrera $E$. Reversion of insulin resistance in the rat during late pregnancy by 72-h glucose infusion. Am J Physiol Endocrinol Metab. 1995;269:E858-63.

43. Herrera E, Lasunción MA, Palacín M, Zorzano A, Bonet B. Intermediary metabolism in pregnancy. First theme of the Freinkel era. Diabetes. $1991 ; 40: 83-8$.

44. Lasuncion MA, Lorenzo J, Palacin M, Herrera E. Maternal factors modulating nutrient transfer to fetus. Biol Neonate. 1987;51:86-93.

45. Cohen B, Novick D, Rubinstein M. Modulation of insulin activities by leptin. Science. 1996;274:1185-8.

46. Henson MC, Castracane VD. Leptin in pregnancy. Biol Reprod. 2000; 63:1219-28.
47. Ladyman SR, Grattan DR. Region-specific reduction in leptin-induced phosphorylation of signal transducer and activator of transcription-3 (STAT3) in the rat hypothalamus is associated with leptin resistence during pregnancy. Endocrinology. 2004;145:3704-11.

48. Grattan DR, Ladyman SR, Augustine RA. Hormonal induction of leptin resistance during pregnancy. Physiol Behav. 2007;91:366-74.

49. Smith TJ, Waddel JB. Leptin distribution and metabolism in the pregnant rat: transplacental leptin passage increases in late gestation but is reduced by excess glucocorticoids. Endocrinology. 2003;144:3024-30.

50. Mello MAR, Almeida PBL. Desnutrição protéica fetal/neonatal, ação da insulina e homeostase glicêmica na vida adulta: efeitos do jejum e do exercício agudo. Rev Bras Educ Fis Esp SP. 2004;18:17-30.

51. Twinn FSD, Ozanne ES, Ekizoglou S, Doherty C, James L, Gusterson B, et al. The maternal endocrine environment in the low-protein model of intra-uterine growth restriction. Br J Nutr. 2003;90:815-22.

52. Grattan DR, Steyn FJ, Kokay IC, Anderson GM, Bunn SJ. Pregnancy-induced adaptation in the neuroendocrine control of prolactin secretion. J Neuroendocrinol. 2008;20:497-507.

53. Benito M, Lorenzo M, Medina JM. Relationship between lipogenesis and glycogen synthesis in maternal and fetal tissues during late gestation in the rat. Effect of dexamethasone. Horm Metab Res. 1982;14:614-5. 